\title{
Genetic variants in ADAM33 are associated with airway inflammation and lung function in COPD
}

\author{
Xinyan Wang ${ }^{1 \dagger}$, Wan $\mathrm{Li}^{2 \dagger}$, Kun Huang ${ }^{1}$, Xiaowen Kang ${ }^{1}$, Zhaoguo $\mathrm{Li}^{1}$, Chengcheng Yang ${ }^{1}$, Xiaomei $\mathrm{Wu}^{1 *}$ \\ and Lina Chen ${ }^{2 *}$
}

\begin{abstract}
Background: Genetic factors play a role in the development and severity of chronic obstructive pulmonary disease (COPD). The pathogenesis of COPD is a multifactorial process including an inflammatory cell profile. Recent studies revealed that single nucleotide polymorphisms (SNPs) within ADAM33 increased the susceptibility to COPD through changing the airway inflammatory process and lung function.
\end{abstract}

Methods: In this paper, we investigated associations of four polymorphisms (T1, T2, S2 and Q-1) of ADAM33 as well as their haplotypes with pulmonary function and airway inflammatory process in an East Asian population of patients with COPD.

Results: We found that T1, T2 and Q-1 were significantly associated with the changes of pulmonary function and components of cells in sputum of COPD, and T1 and Q-1 were significantly associated with cytokines and mediators of inflammation in airway of COPD in recessive models. 10 haplotypes were significantly associated with transfer factor of the lung for carbon monoxide in the disease state, 4 haplotypes were significantly associated with forced expiratory volume in one second, and other haplotypes were associated with airway inflammation.

Conclusions: We confirmed for the first time that ADAM33 was involved in the pathogenesis of COPD by affecting airway inflammation and immune response in an East Asian population. Our results made the genetic background of COPD, a common and disabling disease, more apparent, which would supply genetic support for the study of the mechanism, classification and treatment for this disease.

Keywords: Chronic obstructive pulmonary disease, SNP, ADAM33, Haplotype, Pulmonary function, Airway inflammatory process

\section{Background}

Chronic obstructive pulmonary disease (COPD) is defined as a disease state characterized by poorly reversible and progressive airflow limitation that is usually associated with an abnormal inflammatory response of the lung $[1,2]$. Nearly $90 \%$ of COPD is caused by long term cigarette smoking, however, only $25 \%$ of chronic tobacco smokers develop COPD [3]. Additionally, COPD tends to occur more frequently in smokers with a family history of obstructive airways disorders including asthma and COPD. All of these suggest that, besides smoking, there are other

\footnotetext{
* Correspondence: wu.xiaomei@hotmail.com; chenlina@ems.hrbmu.edu.cn

${ }^{\dagger}$ Equal contributors

'Department of Respiratory, the Second Affiliated Hospital of Harbin Medical University, Harbin 150081, China

${ }^{2}$ College of Bioinformatics Science and Technology, Harbin Medical

${ }^{2}$ College of Bioinformatics Science
University, Harbin 150081, China
}

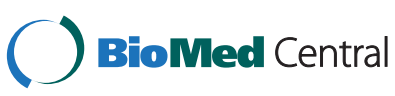

(c) 2014 Wang et al.; licensee BioMed Central Ltd. This is an Open Access article distributed under the terms of the Creative Commons Attribution License (http://creativecommons.org/licenses/by/2.0), which permits unrestricted use, distribution, and reproduction in any medium, provided the original work is properly credited. The Creative Commons Public Domain Dedication waiver (http://creativecommons.org/publicdomain/zero/1.0/) applies to the data made available in this article unless otherwise stated. underlying genetic factors in the development of COPD. Variants of some genes have been investigated and identified to have close associations with COPD, such as TLR-9 [4], HHIP [5], IREB2 and CHRNA3/5 [6].

The pathophysiology of COPD is a multifactorial process with an complex inflammatory cell profile including eosinophils [7], macrophages [8], neutrophils [9], and lymphocytes [10]. The levels of some cytokines, such as interleukin(IL)8 [11], interleukin(IL)-6 [12], tumor necrosis factor alpha (TNF-A) [13], and vascular endothelial growth factor (VEGF) [14] are increased in stable COPD patients, suggesting their key-roles in the pathogenesis of COPD. Therefore, COPD develops as a result of multiple steps involving the inflammatory cells and mediators, in which local inflammation in the lungs is especially important due to affecting airway remodeling and parenchymal destruction.

rass otherwise stated. 
A disintegrin and metalloprotease 33 (ADAM33), a member of the ADAM (a disintegrin and metalloprotease) family, has been identified as an asthma susceptible gene [15]. This finding has been further improved in many populations, such as Indian and Chinese asthma populations $[16,17]$. ADAM proteins are involved in cell adhesion, cell fusion, cell signaling, and proteolysis [18-20]. The latter can be illustrated by the capacity to shed cytokines, growth factors, or their receptors from the cell surface, and the remodeling of extracellular matrix components. Garlisi and colleagues demonstrated that ADAM33 is an active proteinase that is able to cleave $\alpha 2$-macroglobulin [21], an important member of pulmonary defense system. These results suggested that ADAM33 is involved in the pathogenesis of airway obstruction with affecting tissue remodeling, a physiological process intricately related to airway inflammation [22]. Additional studies have demonstrated that single nucleotide polymorphisms (SNPs) within ADAM33 were associated with accelerated decline of lung function in the general population and in asthma patients [23,24]. Recent studies further revealed that SNPs within ADAM33 conferred susceptibility to COPD in the general population through affecting the airway inflammatory process and changing the lung function in COPD [25-28]. Our previous study has further confirmed the association between ADAM33 gene polymorphisms and COPD in the Northeastern Chinese Han population [29]. The aim of this study is to investigate the associations of SNPs in ADAM33 with the severity of the pulmonary function and airway inflammation in patients with COPD.

\section{Methods}

312 patients with stable COPD were recruited for this study. The criteria of the recruitment have been described in detail previously [29], and are shown in Table 1. In brief, all patients had irreversible airflow limitation and chronic respiratory symptoms, and were current or ex-smokers with at least 20 pack-years of smoking. Patients did not use a course of inhaled or oral corticosteroids within 3 months, or maintenance treatment with these drugs within 6 months. None of the patients had a history of asthma. Patients with acute exacerbations two months preceding study assessment were also excluded. Disease severity was classified according to the criteria of Global Initiative for Chronic Obstructive Lung Disease (GOLD) [1]. Approval from the Ethics Committee of Harbin Medical University was obtained before initiating the study. COPD patients were informed of the study protocol and provided written consent.

DNA was extracted from peripheral blood of both COPD patients and control samples, and genotyping was performed as described previously [29] using polymerase chain reaction-restriction fragment length polymorphism (PCR-RFLP) analysis. Based on our previous study [29], the
Table 1 The clinical information of patients recruited

\begin{tabular}{lcc}
\hline & CASE $^{*}$ & CONTROL \\
\hline Number of patients & 312 & 319 \\
Age (years) & $60.5(7.8)$ & $61.5(8.1)$ \\
Male: Female & $186: 126$ & $192: 127$ \\
Pack years of smoking ${ }^{\dagger}$ & $35.46(15.9)$ & $32.54(12.7)$ \\
FEV1 (\% predicted) ${ }^{\ddagger}$ & $52.5(8.6)$ & $91.5(9.6)$ \\
FEV1/FVC (\%) & $47.5(7.6)$ & $90.5(11.6)$ \\
Postbd FEV1 (\% predicted) & $58.5(9.6)$ & $93.5(10.5)$ \\
Postbd FEV1/FVC (\%) & $49.2(8.5)$ & $91.5(11.8)$ \\
TLCO (\% predicted) ${ }^{* *}$ & $63.09(18.1)$ & $93.21(2.9)$ \\
GOLD status & & - \\
Stage I (mild) & 52 & - \\
Stage II (moderate) & 140 & - \\
Stage III (severe) & 98 & - \\
Stage IV (very severe) & 22 & \\
\hline
\end{tabular}

"Data are means and standard deviations (in parentheses).

${ }^{\dagger}$ Pack year: (packs per day) $\times$ (years smoked).

${ }^{\ddagger} \mathrm{FEV} 1$ : forced expiratory volume in first second.

${ }^{5} \mathrm{FVC}$ : forced vital capacity.

"Postbd: post bronchodilator.

${ }^{* *}$ TLCO: transfer factor of the lung for carbon monoxide.

four SNPs in ADAM33 have been genotyped: $\mathrm{Q}-1(\mathrm{C} / \mathrm{T})$, S2 (G/C), T1 (Met-Thr), T2 (Pro-Ser) and the primers used are listed in Table 2.

\section{Sputum induction and processing}

Sputum samples were obtained in the stable clinical state of COPD patients, at least two months after any exacerbation. Following the established standards for inducing sputum [30], patients inhaled 200 ug of salbutamol and afterwards 3\% saline from an ultrasonic nebulizer for three

Table 2 The location of investigated ADAM33 SNPs and primer sequence

\begin{tabular}{|c|c|c|c|c|}
\hline $\begin{array}{l}\text { Chromosome } \\
\text { Position }\end{array}$ & $\begin{array}{l}\text { Reference } \\
\text { SNP ID }\end{array}$ & $\begin{array}{l}\text { SNP } \\
\text { Name }\end{array}$ & Alleles & Primer sequences \\
\hline \multirow{2}{*}{3590205} & \multirow{2}{*}{2280090} & \multirow{2}{*}{$\mathrm{T} 2$} & \multirow{2}{*}{$A / G$} & $\begin{array}{l}\text { F: 5'-TTCTCAGGG } \\
\text { TCTGGGAGAAA-3' }\end{array}$ \\
\hline & & & & $\begin{array}{c}\text { R: 5'-GCCAACCTCC } \\
\text { TGGACTCTTA-3' }\end{array}$ \\
\hline \multirow{2}{*}{3590234} & \multirow{2}{*}{2280091} & \multirow{2}{*}{$\mathrm{T} 1$} & \multirow{2}{*}{$A / G$} & $\begin{array}{c}\text { F: 5'-ACTCAAGGTG } \\
\text { ACTGGGTGCT-3' }\end{array}$ \\
\hline & & & & $\begin{array}{l}\text { R: 5'-GAGGGCATG } \\
\text { AGGCTCACTTG-3' }\end{array}$ \\
\hline \multirow{2}{*}{3591742} & \multirow{2}{*}{528557} & \multirow{2}{*}{ S2 } & \multirow{2}{*}{$C / G$} & $\begin{array}{l}\text { F: 5'-AGAGCTCTGA } \\
\text { GGAGGGGAAC-3' }\end{array}$ \\
\hline & & & & $\begin{array}{l}\text { R: 5'-TGTGCAGGCT } \\
\text { GAAAGTATGC-3' }\end{array}$ \\
\hline \multirow{2}{*}{3592207} & \multirow{2}{*}{612709} & \multirow{2}{*}{ Q-1 } & \multirow{2}{*}{$A / G$} & $\begin{array}{l}\text { F: 5'-GGATTCAAAC } \\
\text { GGCAAGGAG-3' }\end{array}$ \\
\hline & & & & $\begin{array}{l}\text { R: 5'-GTTCACCTAG } \\
\text { ATGGCCAGGA-3' }\end{array}$ \\
\hline
\end{tabular}


10 min periods, unless a $20 \%$ drop in forced expiratory volume in one second (FEV1) occurred. If this occurred, consecutive sputum inductions were performed using $0.9 \%$ saline. Samples produced after the three inhalation periods were processed separately and pooled values were derived by weighted averaging [31].

All adequate plugs of sputum were selected. After incubation with Sputolysin TM, Giemsa-stained cytospins were prepared. Non-squamous cells were counted by two independent observers, and the average of the values was taken for analysis. The levels of IL-6, IL-8, TNF-a and VEGF in sputum supernatants were determined in adequately diluted samples by ELISA (U.S. TPI kit).

\section{Lung function measurement}

Pulmonary function testing of both COPD patients and control samples was evaluated on a Jaeger Transfer screen II (Erich Jaeger GmbH, Würzburg, Germany) and included: total lung volume; FEV1; vital capacity (VC); forced vital capacity (FVC); peak expiratory flow (PEF); and transfer factor of the lung for carbon monoxide (TLCO). Evaluation of the pulmonary function is relied on standards established by the Chinese Medical Association. The mean standard residual values of FEV1 are normally distributed and independent of height, age and gender.

\section{Data analysis}

We first tested whether SNPs were in Hardy-Weinberg equilibrium. Logistic regression analyses were then performed to test the association between each SNP with COPD case/control status, and linear regression analyses were performed to assess the relationships between SNPs and quantitative phenotypes, i.e. pulmonary function measurements (percent predicted (pp) FEV1, ppFVC, and ppTLCO), inflammatory cells (eosinophils, lymphocyte, macrophage, neutrophil and sputum) and cytokines in sputum (IL-8, IL-6, TNFA and VEGF). Both regression analyses were adjusted based on the age, sex and pack-years smoked. Three genetic models were used: dominate model (homozygotes and heterozygotes for the minor allele being compared as a group with homozygotes for the major allele), codominant model (three genotype groups per SNP separately) and recessive model (homozygotes and heterozygotes for the major allele being compared as a group with homozygotes for the minor allele). Statistical analysis was performed using the PLINK software (version 1.07, http://pngu.mgh.harvard.edu/purcell/plink/) [32], and haplotype analysis was also conducted using the same software. $\mathrm{P}<0.05$ was considered statistically significant.

\section{Results}

All genotype frequencies were consistent with HardyWeinberg equilibrium ( $\mathrm{p}>0.01)$. T1, T2 and Q-1 were significantly associated with COPD $(\mathrm{p}<0.00004)$ adjusted for sex, age and pack-years smoked. In addition to controlling the p-value by the Benjamini-Hochberg method, we performed an alternative adjustment for multiple comparisons using a permutation-based approach. After this adjustment, these three SNPs still show significant associations with COPD (adjusted $\mathrm{p}<0.00005$ ).

Results of multiple regression analyses assuming a dominant model and codominant model are shown in the Additional file 1. Multiple regression analyses assuming a recessive model are presented below.

\section{Association of ADAM33 SNPs with inflammatory cells in sputum}

The analysis was conducted among cases only. The results showed that T1 was significantly associated with the percentage of lymphocyte $(\mathrm{p}=0.03), \mathrm{Q}-1$ was associated with the percentage of macrophage $(\mathrm{p}=0.02)$, and T2 was associated with total cell count in sputum $(\mathrm{p}=0.03)$ under a recessive genetic model. T2 and T1 showed a trend toward association for the percentage of lymphocyte $(\mathrm{p}=0.06)$ and total cell count in sputum ( $\mathrm{p}=0.07)$, respectively (Figure 1 ). However, no other significant association between these SNPs and other type of inflammatory cells was observed.

\section{Association of ADAM33 SNPs with cytokines in sputum}

There were no significant associations between IL- 6 and these SNPs in recessive models. In contrast, the T1 SNP showed a significant association with IL-8 $(\mathrm{p}<0.01)$ in subjects with COPD. The Q-1 SNP was associated with IL-8, TNF-A and VEGF ( $<<0.01$ ) (Figure 2). T2 and S2 were not associated with cytokines in sputum.

\section{Association ofADAM33 SNPs with pulmonary function}

The significant pulmonary functions were identified in the patients with any SNPs in comparison to the control samples. T2 and T1 were significantly associated with ppFEV1 (Figure 3), ppFEV1/FVC (Figure 4) and ppTLCO (Figure 5) within COPD cases in recessive models $(\mathrm{p}<0.05)$. The Q-1 SNP was also significantly associated with ppTLCO $(\mathrm{p}<0.01)$. When examining control samples only, there was no significant association between these SNPs and any of the measures of lung function.

\section{Haplotype association analysis}

The haplotype associations with pulmonary function or inflammatory processes were investigated. 8 haplotypes on T2, T1, S2 and Q-1 were significantly different between cases and controls in either the crude analysis or the analysis adjusting for age, gender and smoking. Other 3 haplotypes were significantly different in the analysis adjusting for age, gender and smoking (Table 3).

We investigated associations of haplotypes with cell count and cytokines in sputum with patients of COPD. GAGG, AGGG, AACG, AGCG and GGCA were found to 


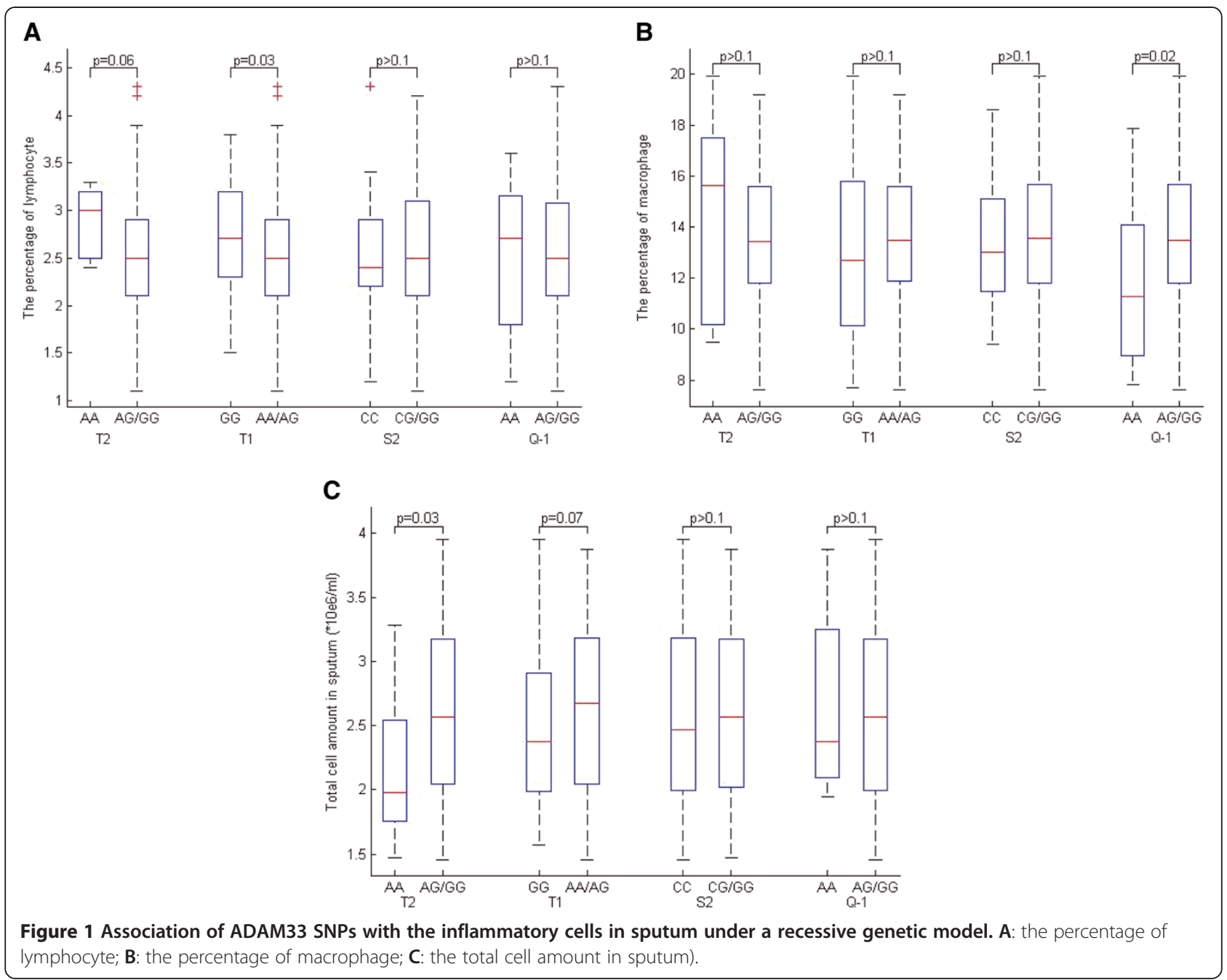

be significantly associated with total cell count in sputum, GAGG was significantly associated with the percentage of lymphocyte, GACG was significantly associated with TNF-A, GACA, AAGA and GAGA were significantly associated with VEGF, and GAGG, AACG and AGCG was significantly associated with IL- 8 in the analysis adjusting for age, gender and smoking (Table 4).

We investigated associations of haplotypes with pulmonary function in COPD and controls in the analysis adjusted for age, gender and smoking. Only GAGA was significantly associated with ppFEV1 in the normal state. 10 haplotypes were significantly associated with ppTLCO in the disease state, 4 haplotypes (AAGG, GGCA, GGGA and AACG) were significantly associated with ppFEV1 and ppFEV1/FVC, while only GGGG was significantly associated with ppFEV1. AAGG, GGCA and GGGA were significantly associated with pulmonary functions (FEV1, FEV1/FVC and TLCO) (Table 5).

9 different haplotypes (except GACA and GACG) were significantly associated with TLCO in either the crude analysis or the analysis adjusting for age, gender and smoking.

\section{Discussion}

To our knowledge, this is the first study to show significant association between four polymorphisms (T1, T2, S2 and Q-1) of ADAM33 as well as their haplotypes and pulmonary function and airway inflammation of patients with COPD in an East Asian population. We first found that $\mathrm{T} 1, \mathrm{~T} 2$ and Q-1 were significantly associated with COPD, while Figarsk et al. revealed that S1, S2, T2 and Q-1 were significantly associated with COPD in Vlagtwedde/Vlaardingen cohort [25]. Since no association was found between S1 and COPD in our previous study in a northeastern Chinese population [29], we did not include S1 in this study. We also found that T1, T2 and Q-1 were significantly associated with pulmonary function and components of cells in sputum of COPD, and T1 and Q-1 were significantly associated with cytokines and mediators of inflammation in airway of COPD 


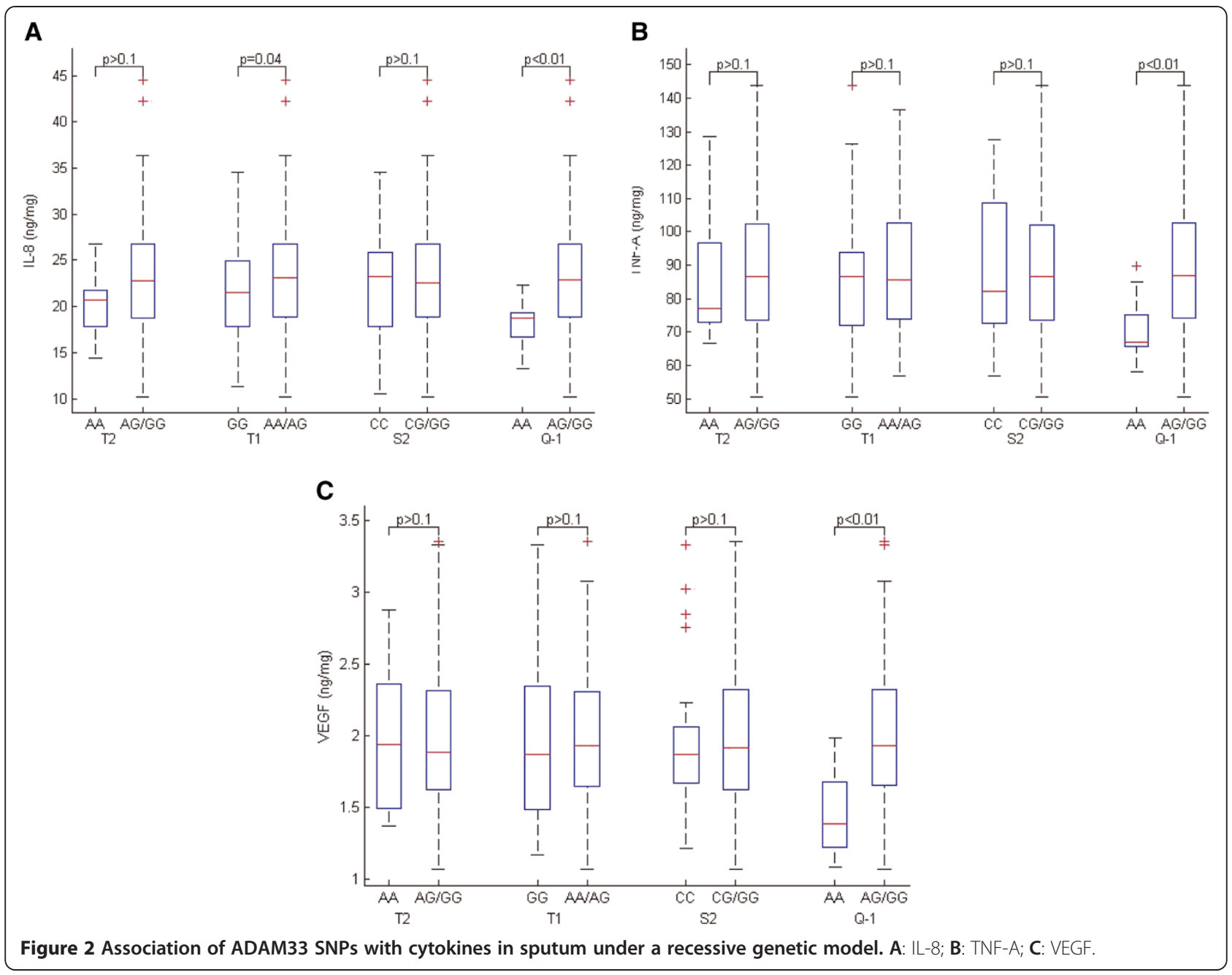

in recessive models. These results suggest ADAM33 gene involved in the pathogenesis of COPD and multiple SNPs loci of interaction could promote the progress of COPD.

ADAM33 is a member of the zinc-dependent metalloproteinase ADAM superfamily, which regulate their own function and a wide range of other proteins through proteolytic cleavage [33]. ADAM33 has multiple domains including prodomain, catalytic, metalloprotease, disintegrin (binds integrins), cysteine-rich/epidermal growth factor (cell-cell contact), transmembrane, and cytoplasmic domains, and has multiple splice forms containing various combinations of these domains. ADAM33 is predominantly expressed in airway structural cells, including airway epithelium, airway smooth muscle (ASM), myofibroblasts, and fibroblasts, and is thought to have a wide spectrum of functions, such as protease-dependent and independent mechanisms. ADAMs cleaves proteins from the cell surface and might facilitate release of cytokines and growth factors. The pathogenesis of COPD involves the recruitment and regulation of neutrophils, macrophages, and lymphocytes to the lung, as well as the induction of imbalance between proteinases and antiproteinases, all of which result in lung parenchymal destruction and airway remodeling. Based on the expression profile and functions, ADAM33 is involved in pathogenesis of COPD. Our study showed that the SNP T1 is significantly associated with macrophage and T2 is significantly associated with total cells in sputum of patients with COPD, Q-1 was significantly associated with IL-8, TNF-A and VEGF in sputum of COPD. Therefore, like other ADAMs, ADAM33 can promote the release of cytokines and growth factors, lead to inflammatory cells infiltration in the airway. In addition, soluble ADAM33 has been implicated in angiogenesis [22] and new vessels, and may promote inflammatory cells and cytokines or growth factors in the airway. Although not as well studied, there is evidence that the vascular areas of the airway is significantly increased in COPD and are related to the degree of airflow obstruction [34]. In this current study, our results showed that T1 and Q-1 affected lymphocyte and macrophage, implying that ADAM33 might affect the immune response of the airways and further promote the formation of COPD. Some studies have also found the association between 

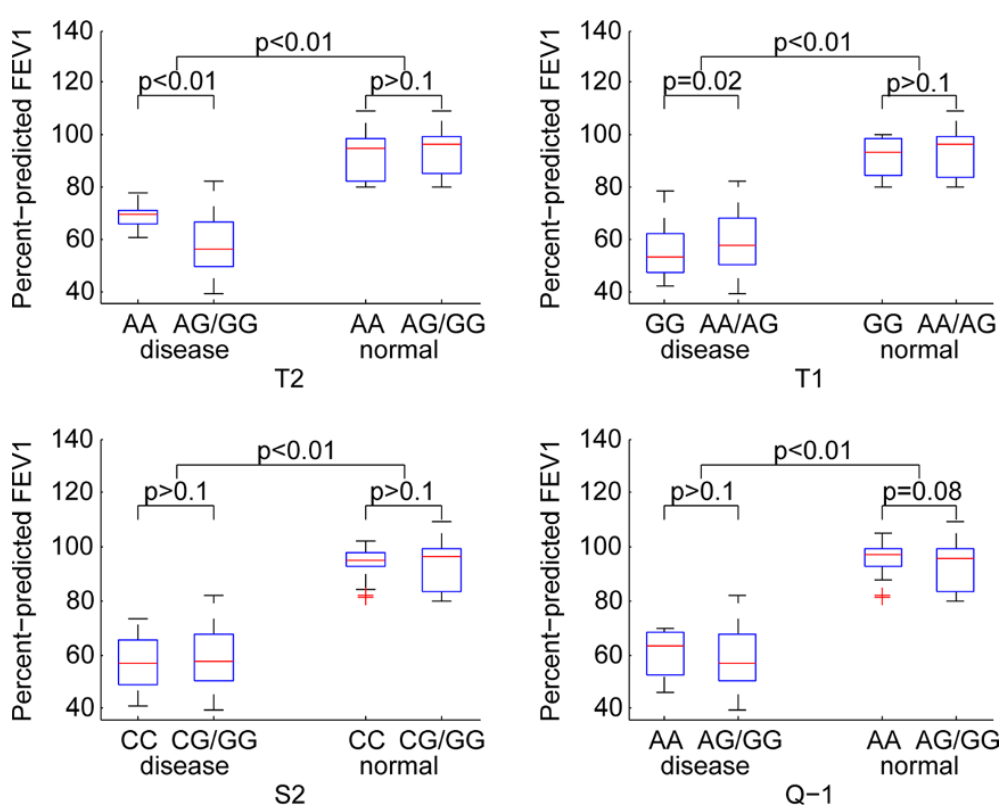

Figure 3 Association of ADAM33 SNPs with ppFEV1 under a recessive genetic model.

macrophage and lymphocytes and immune responses of COPD. For example, Winkler et al. found that the products of activated macrophages have also been implicated in inflammation and tissue destruction, including in COPD [35]. Domagala-Kulawik et al. showed in their study that macrophages were involved in the inflammatory process caused by smoking in COPD and were associated with severe airflow limitation [36].
In the airway of patients with COPD, the inflammation limits the airflow and further causes a loss of lung function of COPD. It is known that pulmonary function decline is a prominent characteristic for the development of COPD and cardiovascular disease [37]. Our data confirmed that $\mathrm{T} 1$ and $\mathrm{T} 2$ were significantly associated with decreased FEV1 and FEV1/FVC, T2, T1 and Q-1 were significantly associated with decreased TLCO. The study
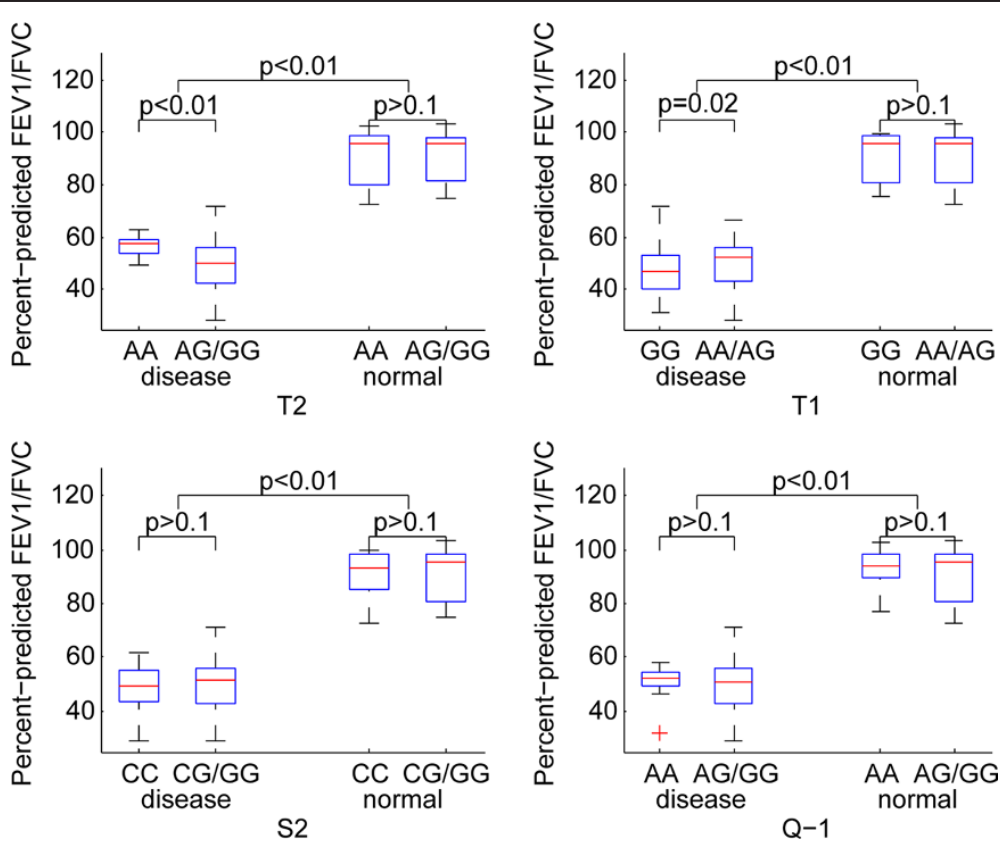

Figure 4 Association of ADAM33 SNPs with ppFEV1/FVC under a recessive genetic model. 

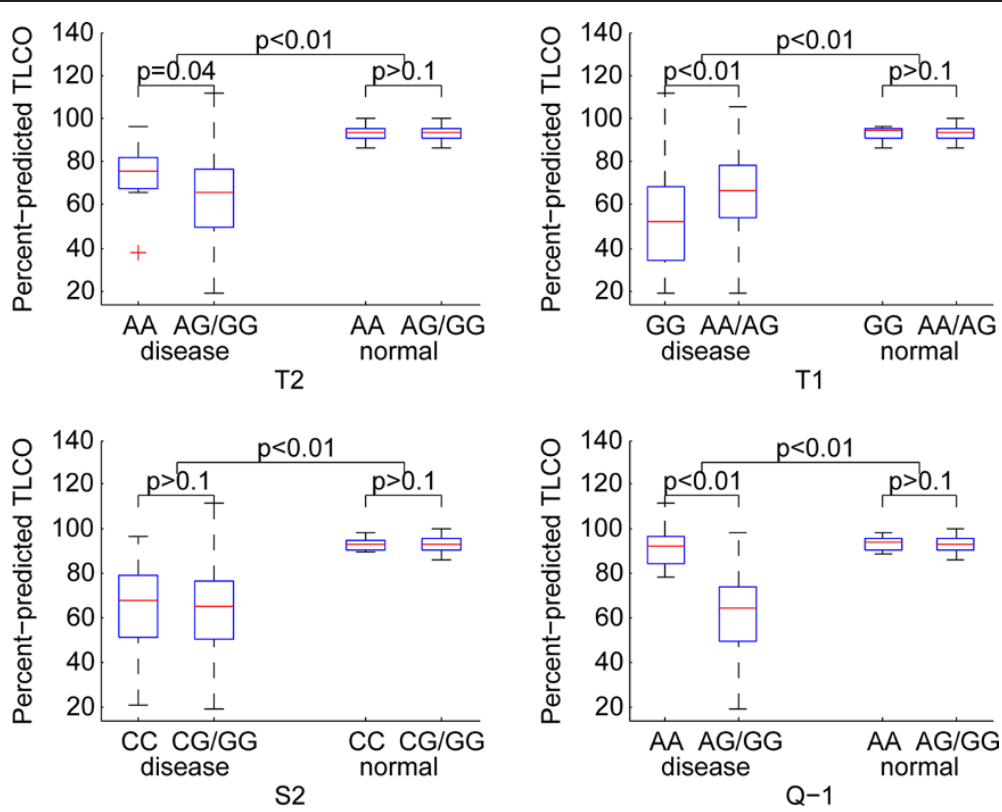

Figure 5 Association of ADAM33 SNPs with ppTLCO under a recessive genetic model.

conducted by Jongepier $\mathrm{H}$ and colleagues found similar results in asthmatic patients [38]. It is important to note that ADAM33 SNPs have also shown associations with excess FEV1 decline in general population samples. The main SNPs identified included Q-1, S1, S2 with excess decline of 23.6 to $9.6 \mathrm{~mL} / \mathrm{y}$. S1 and S2 were associated with COPD in this population, reflecting the potential

Table 3 Association of haplotypes with COPD in both the crude and the adjusted analysis

\begin{tabular}{cccccc}
\hline & & & & \multicolumn{2}{c}{ P-value } \\
\cline { 5 - 6 } T2 & T1 & S2 & Q-1 & Unadjusted & Adjusted $^{*}$ \\
\hline G & G & G & G & $3.734 \mathrm{e}-011$ & $1.1 \mathrm{e}-013$ \\
G & G & C & G & $6.32 \mathrm{e}-009$ & $1.72 \mathrm{e}-011$ \\
A & A & G & A & $3.514 \mathrm{e}-006$ & $3.76 \mathrm{e}-007$ \\
A & A & G & G & $5.16 \mathrm{e}-006$ & $8.81 \mathrm{e}-007$ \\
G & A & G & A & 0.003103 & 0.0016 \\
A & A & C & A & 0.004037 & 0.000244 \\
A & G & G & A & 0.04011 & 0.00803 \\
G & A & C & A & 0.01269 & 0.00398 \\
G & G & C & A & - & 0.00712 \\
G & G & G & A & - & 0.0131 \\
G & A & C & G & - & 0.026 \\
G & A & G & G & - & \\
A & A & C & G & - & \\
A & G & G & G & - & \\
A & G & C & G & - & \\
\hline
\end{tabular}

${ }^{\bar{*}}$ The analysis adjusted for age, gender and smoking. role of ADAM33 in airway remodeling in multiple respiratory diseases. Emphysema is another main pathological condition for COPD [39]. It's worth noting that, in comparison to other studies, our study also identified the relationship between SNP and TLCO of COPD since TLCO associated with the severity of emphysema. We found that T2, T1 and Q-1 were associated with decreased TLCO of COPD, suggesting that the ADAM33 also play a role in the pathogenesis of emphysema. An imbalance of endogenous proteinases and antiproteinases is considered to be a major mechanism for emphysematous lung destruction. In this context, matrix metalloproteinase have aroused interest due to their capability of inducing emphysema by proteolysis of lung parenchyma. Similar to matrix metalloproteinase, the ADAM family possesses proteolytic and adhesive activity. As a member of this gene family, any alterations of ADAM33 may affect the regulation of cell-cell and cell-matrix adhesion and the extent of extracellular matrix degradation. Therefore, it is conceivable that mutations in ADAM33 might promote emphysematous changes, a main phenotype or pathologic change of COPD.

We found that T1, T2 and Q-1 were significantly associated with COPD. The SNP Q-1 is located in the intron immediately before exon 16, which contains an epidermal growth factor (EGF) domain [40]. EGFR signaling regulates matrix metalloprotease, which mediates epithelial-mesenchymal interactions during lung morphogenesis [41]. The mice lacking the EGF receptor (EGFR) demonstrate abnormal branching and poor alveolarization. ADAM33 is closely related to matrix metalloprotease, but may bind EGF 
Table 4 Association of haplotypes with inflammatory cells and cytokines in sputum in the adjusted analysis

\begin{tabular}{|c|c|c|c|c|c|c|c|c|c|c|c|c|}
\hline \multirow[b]{2}{*}{ T2 } & \multirow[b]{2}{*}{$\mathrm{T} 1$} & \multirow[b]{2}{*}{ S2 } & \multirow[b]{2}{*}{ Q-1 } & \multicolumn{9}{|c|}{ P-value } \\
\hline & & & & Sputum & Neutrophil & Macrophage & Lymphocyte & Eosinophils & TNF-A & VEGF & IL-6 & IL-8 \\
\hline G & A & G & G & 0.00207 & & & 0.0239 & & & & & $7.07 e-006$ \\
\hline A & A & C & G & 0.00598 & & & & & & & & 0.0322 \\
\hline A & G & G & G & 0.00823 & & & & & & & & \\
\hline A & G & C & G & 0.0146 & & & & & & & & 0.0435 \\
\hline G & G & C & A & 0.0349 & & & & & & & & \\
\hline G & A & C & G & & & & & & 0.0338 & & & \\
\hline G & A & C & A & & & & & & & 0.00419 & & \\
\hline A & A & G & A & & & & & & & 0.0188 & & \\
\hline G & A & G & A & & & & & & & 0.0361 & & \\
\hline
\end{tabular}

directly. Through alterative splicing, exon 16 can be spliced out, giving rise to the $\beta$-variant of ADAM33. This variant was found in $30 \%$ of ADAM33 mRNA transcripts in pulmonary fibroblasts [42]. The intronic Q-1 SNP has been identified to influence the splicing of the $\beta$-variant [43], and disturb the maturation of ADAM33. Because the EGF domain is incomplete, it has been suggested that the $\beta$-variant prevents maturation of ADAM33 and may exert a dominant-negative effect on its protease activity [44]. Subsequent effects on protease activity may result in a defect in tissue repair after inflammation-induced damage. This may lead to progressive destruction of alveolar tissue and thereby enhance accelerated decline in lung function of COPD.

The T1 and T2 SNPs are located in the exon 19 (which includes an SH3 domain and a phosphorylation site) of the cytoplasmic tail, which may affect signaling [29]. T1, T2 are in the domain Reprolysin family propeptide, which interacts with 5 domains, including Thrombospondin, C-type lection and ADAM-TS Spacer 1. Thrombospondin
1 is an antiangiogenic factor, which can inhibit the proliferation and migration of endothelial cells. Angiogenesis is a key process in the evolution and maintenance of psoriasis and other chronic inflammatory diseases, such as inflammatory bowel disease, chronic obstructive pulmonary disease, and rheumatoid arthritis [45]. Proteins that contain C-type lectin domains have a diverse range of functions including cell-cell adhesion, immune response to pathogens and apoptosis. Apoptosis has been recognized to play an important role in clinical and experimental models of lung diseases [46]. Recently many reports have been published highlighting the presence of apoptosis in human COPD lungs and its role in the pathogenesis of emphysema [47]. ADAM-TS Spacer1 represents the Spacer-1 region from the ADAM-TS family of metalloproteinase and ADAM-TS family has some lung-related biological actions [48].

In this current study, we also analyzed associations between haplotypes of four polymorphisms (T1, T2, S2 and Q-1) in ADAM33 and pulmonary function and airway

Table 5 Association of haplotypes with pulmonary function in the analysis adjusted for age, gender and smoking

\begin{tabular}{|c|c|c|c|c|c|c|c|c|c|}
\hline \multirow{3}{*}{$\mathrm{T} 2$} & \multirow{3}{*}{$\mathrm{T} 1$} & \multirow{3}{*}{ S2 } & \multirow{3}{*}{ Q-1 } & \multicolumn{6}{|c|}{ P-value } \\
\hline & & & & Percent-predicted FEV1 & FEV1/FVC & $\begin{array}{l}\text { Percent-predicted } \\
\text { TLCO }\end{array}$ & Percent-predicted FEV1 & FEV1/FVC & $\begin{array}{c}\text { Percent-predicted } \\
\text { TLCO }\end{array}$ \\
\hline & & & & \multicolumn{3}{|c|}{ Disease } & \multicolumn{3}{|c|}{ Normal } \\
\hline G & G & G & G & 0.0247 & - & $1.04 \mathrm{e}-005$ & - & - & - \\
\hline G & G & C & G & - & - & 0.000205 & - & - & - \\
\hline A & A & G & A & - & - & 0.000368 & - & - & - \\
\hline$A$ & $A$ & G & G & 0.00176 & 0.000154 & $1.67 \mathrm{e}-007$ & - & - & - \\
\hline A & $A$ & $\mathrm{C}$ & A & - & - & 0.000224 & - & - & - \\
\hline G & $A$ & G & $A$ & - & - & - & 0.005447 & - & - \\
\hline G & G & C & $A$ & 0.000234 & 0.000272 & $1.22 \mathrm{e}-005$ & - & - & - \\
\hline A & G & G & A & - & - & 0.0392 & - & - & - \\
\hline G & G & G & A & $8.68 e-005$ & 0.00209 & $6.98 e-016$ & - & - & - \\
\hline G & A & G & G & - & - & 0.00319 & - & - & - \\
\hline$A$ & $A$ & C & G & 0.0154 & 0.0465 & 0.0014 & - & - & - \\
\hline
\end{tabular}


inflammation of patients with COPD. GAGG, AGGG, AACG, AGCG and GGCA were found to be significantly associated with total cell count in sputum: GAGG was significantly associated with increase lymphocyte count; GACG was significantly associated with increased level of TNF-A; GACA, AAGA and GAGA were significantly associated with VEGF; and GAGG, AACG and AGCG was significantly associated with IL-8 in the analysis adjusted for age, gender and smoking. These results demonstrated that multiple SNPs could work together to promote airway inflammation of patients with COPD. It is worth noting that 10 haplotypes were found to be significantly associated with ppTLCO in the disease state, 5 of these haplotypes (AAGG, GGCA, GGGA, AACG and GGGG) were significantly associated with ppFEV1, and 4 haplotypes (AAGG, GGCA, GGGA and AACG) were significantly associated with ppFEV1/FVC. These results indicated that although there were no common associations between single SNP and inflammatory cells in sputum, haplotypes of these SNPs were found to be associated with the quantitative traits. COPD high-risk groups could be screened out using these haplotypes of ADAM33 in the future, though much effort should be put into this clinical field.

We focused on the association of four polymorphisms (T1, T2, S2 and Q-1) of ADAM33 as well as their haplotypes with pulmonary function and airway inflammation of patients with COPD, thus, no sputum cells were obtained from control samples. More comprehensive data should be obtained to reveal the mechanism of COPD in further study.

\section{Conclusions}

In this paper, we confirmed for the first time that ADAM33 was involved in the pathogenesis of COPD in an East Asian population by affecting airway inflammation and immune response. Our results made the genetic background of COPD, a common and disabling disease, more apparent, which would supply genetic support for the study of mechanism, classification and treatment for this disease.

\section{Additional file}

Additional file 1: Results of multiple regression analyses assuming

a dominant model and codominant model.

\section{Competing interests}

The authors declare that they have no competing interests.

\section{Authors' contributions}

XW and WL participated in the design of the study and performed the statistical analysis. XW and LC conceived of the study, and participated in its design and coordination and helped to draft the manuscript. $\mathrm{KH}, \mathrm{XK}, \mathrm{ZL}$ and CY collected specimen. All authors read and approved the final manuscript.

\section{Acknowledgements}

This work was supported by the National Natural Science Foundation of China (Grant No. 61272388), and the Natural Science Foundation of Heilongjiang Province (Grant No. F201237).

Received: 22 October 2013 Accepted: 20 October 2014

Published: 4 November 2014

\section{References}

1. Vestbo J, Hurd SS, Agusti AG, Jones PW, Vogelmeier C, Anzueto A, Barnes PJ, Fabbri LM, Martinez FJ, Nishimura M, Stockley RA, Sin DD, Rodriguez-Roisin R: Global strategy for the diagnosis, management, and prevention of chronic obstructive pulmonary disease: GOLD executive summary. Am J Respir Crit Care Med 2013, 187:347-365.

2. Rabe KF, Hurd S, Anzueto A, Barnes PJ, Buist SA, Calverley P, Fukuchi Y Jenkins C, Rodriguez-Roisin R, van Weel C, Zielinski J: Global strategy for the diagnosis, management, and prevention of chronic obstructive pulmonary disease: GOLD executive summary. Am J Respir Crit Care Med 2007, 176:532-555.

3. Lokke A, Lange P, Scharling H, Fabricius P, Vestbo J: Developing COPD: a 25 year follow up study of the general population. Thorax 2006, 61:935-939.

4. Pabst S, Bradler O, Gillissen A, Nickenig G, Skowasch D, Grohe C: Toll-like receptor-9 polymorphisms in sarcoidosis and chronic obstructive pulmonary disease. Adv Exp Med Biol 2013, 756:239-245.

5. Kim WJ, Oh YM, Lee JH, Park CS, Park SW, Park JS, Lee SD: Genetic variants in HHIP are associated with FEV1 in subjects with COPD. Respirology 2013, 18:1202-1209

6. Zhou H, Yang J, Li D, Xiao J, Wang B, Wang L, Ma C, Xu S, Ou X, Feng Y: Association of IREB2 and CHRNA3/5 polymorphisms with COPD and COPD-related phenotypes in a Chinese Han population. J Hum Genet 2012, 57:738-746.

7. Bafadhel M, McKenna S, Terry S, Mistry V, Pancholi M, Venge P, Lomas DA, Barer MR, Johnston SL, Pavord ID, Brightling CE: Blood eosinophils to direct corticosteroid treatment of exacerbations of chronic obstructive pulmonary disease: a randomized placebo-controlled trial. Am J Respir Crit Care Med 2012, 186:48-55.

8. Kojima J, Araya J, Hara H, Ito S, Takasaka N, Kobayashi K, Fujii S, Tsurushige C, Numata T, Ishikawa T, Shimizu K, Kawaishi M, Saito K, Kamiya N, Hirano J, Odaka M, Morikawa T, Hano H, Arai S, Miyazaki T, Kaneko Y, Nakayama K, Kuwano K: Apoptosis inhibitor of macrophage (AIM) expression in alveolar macrophages in COPD. Respir Res 2013, 14:30.

9. Mallia P, Message SD, Contoli M, Gray KK, Telcian A, Laza-Stanca V, Papi A, Stanciu $L A$, Elkin S, Kon OM, Johnson M, Johnston SL: Neutrophil adhesion molecules in experimental rhinovirus infection in COPD. Respir Res 2013, 14:72.

10. Manral S, Bhatia S, Sinha R, Kumar A, Rohil V, Arya A, Dhawan A, Arya P, Joshi R, Sreedhara SC, Gangopadhyay S, Bansal SK, Chatterjee S, Chaudhury NK, Vijayan VK, Saso L, Parmar VS, DePass AL, Prasad AK, Raj HG: Normalization of deranged signal transduction in lymphocytes of COPD patients by the novel calcium channel blocker H-DHPM. Biochimie 2011, 93:1146-1156

11. Nadigel J, Audusseau S, Baglole CJ, Eidelman DH, Hamid Q: IL-8 production in response to cigarette smoke is decreased in epithelial cells from COPD patients. Pulm Pharmacol Ther 2013, 26:596-602.

12. Hubeau C, Kubera JE, Masek-Hammerman K, Williams CM: Interleukin-6 neutralization alleviates pulmonary inflammation in mice exposed to cigarette smoke and poly(l:C). Clin Sci (Lond) 2013, 125:483-493.

13. Zhang PF, Pan L, Luo ZY, Zhao HJ, Cai SX: Interrelationship of circulating matrix metalloproteinase-9, TNF-a, and OPG/RANK/RANKL systems in COPD patients with osteoporosis. Copd 2013, 10:650-656.

14. Lee CG, Ma B, Takyar S, Ahangari F, Delacruz C, He CH, Elias JA: Studies of vascular endothelial growth factor in asthma and chronic obstructive pulmonary disease. Proc Am Thorac Soc 2011, 8:512-515.

15. Holgate ST, Yang Y, Haitchi HM, Powell RM, Holloway JW, Yoshisue H, Pang YY, Cakebread J, Davies DE: The genetics of asthma: ADAM33 as an example of a susceptibility gene. Proc Am Thorac Soc 2006, 3:440-443.

16. Chi X, Wang L, Wang J, Li Q, Wang X, Xiao W: Association of ADAM33 gene polymorphisms with asthma in a Chinese population. Clin Respir $J$ 2013, 7:16-20.

17. Tripathi P, Awasthi S, Prasad R, Ganesh S: Haplotypic association of ADAM33 $(T+1, S+1$ and $V-3)$ gene variants in genetic susceptibility to asthma in Indian population. Ann Hum Biol 2012, 39:479-483. 
18. Przemyslaw L, Boguslaw HA, Elzbieta S, Malgorzata SM: ADAM and ADAMTS family proteins and their role in the colorectal cancer etiopathogenesis. BMB Rep 2013, 46:139-150.

19. Miller MA, Meyer AS, Beste MT, Lasisi Z, Reddy S, Jeng KW, Chen CH, Han J, Isaacson K, Griffith LG, Lauffenburger DA: ADAM-10 and -17 regulate endometriotic cell migration via concerted ligand and receptor shedding feedback on kinase signaling. Proc Natl Acad Sci U S A 2013, 110:E2074-E2083.

20. Christian LM: The ADAM family: insights into Notch proteolysis. Fly 2012, 6:30-34.

21. Garlisi CG, Zou J, Devito KE, Tian F, Zhu FX, Liu J, Shah H, Wan Y, Motasim Billah M, Egan RW, Umland SP: Human ADAM33: protein maturation and localization. Biochem Biophys Res Commun 2003, 301:35-43.

22. Puxeddu I, Pang YY, Harvey A, Haitchi HM, Nicholas B, Yoshisue H, Ribatti D, Clough G, Powell RM, Murphy G, Hanley NA, Wilson DI, Howarth PH, Holgate ST, Davies DE: The soluble form of a disintegrin and metalloprotease 33 promotes angiogenesis: implications for airway remodeling in asthma. J Allergy Clin Immunol 2008, 121:1400-1406. 1406 e1401-1404.

23. Miyake Y, Tanaka K, Arakawa M: ADAM33 polymorphisms, smoking and asthma in Japanese women: the Kyushu Okinawa Maternal and Child Health Study. Int J Tuberc Lung Dis Off J Int Union Against Tuberc Lung Dis 2012, 16:974-979.

24. Reijmerink NE, Kerkhof M, Koppelman GH, Gerritsen J, de Jongste JC, Smit HA, Brunekreef B, Postma DS: Smoke exposure interacts with ADAM33 polymorphisms in the development of lung function and hyperresponsiveness. Allergy 2009, 64:898-904.

25. Figarska SM, Vonk JM, van Diemen CC, Postma DS, Boezen HM: ADAM33 gene polymorphisms and mortality. A prospective cohort study. PloS one 2013, 8:e67768.

26. Sadeghnejad A, Ohar JA, Zheng SL, Sterling DA, Hawkins GA, Meyers DA, Bleecker ER: Adam33 polymorphisms are associated with COPD and lung function in long-term tobacco smokers. Respir Res 2009, 10:21.

27. Gosman MM, Boezen HM, van Diemen CC, Snoeck-Stroband JB, Lapperre TS, Hiemstra PS, Ten Hacken NH, Stolk J, Postma DS: A disintegrin and metalloprotease 33 and chronic obstructive pulmonary disease pathophysiology. Thorax 2007, 62:242-247.

28. van Diemen CC, Postma DS, Vonk JM, Bruinenberg M, Schouten JP, Boezen HM: A disintegrin and metalloprotease 33 polymorphisms and lung function decline in the general population. Am J Respir Crit Care Med 2005, 172:329-333

29. Wang X, Li L, Xiao J, Jin C, Huang K, Kang X, Wu X, Lv F: Association of ADAM33 gene polymorphisms with COPD in a northeastern Chinese population. BMC Med Genet 2009, 10:132.

30. Black RA, White JM: ADAMs: focus on the protease domain. Curr Opin Cell Biol 1998, 10:654-659.

31. Holz O, Jorres RA, Koschyk S, Speckin P, Welker L, Magnussen H: Changes in sputum composition during sputum induction in healthy and asthmatic subjects. Clin Exp Allergy J Br Soc Allergy Clin Immunol 1998, 28:284-292.

32. Purcell S, Neale B, Todd-Brown K, Thomas L, Ferreira MA, Bender D, Maller J, Sklar P, de Bakker PI, Daly MJ, Sham PC: PLINK: a tool set for whole-genome association and population-based linkage analyses. Am J Hum Genet 2007, 81:559-575.

33. Holgate ST, Davies DE, Powell RM, Holloway JW: ADAM33: a newly identified protease involved in airway remodelling. Pulm Pharmacol The 2006, 19:3-11.

34. Hashimoto M, Tanaka H, Abe S: Quantitative analysis of bronchial wall vascularity in the medium and small airways of patients with asthma and COPD. Chest 2005, 127:965-972.

35. Winkler $A R$, Nocka KH, Sulahian $T H$, Kobzik L, Williams CM: In vitro modeling of human alveolar macrophage smoke exposure: enhanced inflammation and impaired function. Exp Lung Res 2008, 34:599-629.

36. Domagala-Kulawik J, Maskey-Warzechowska M, Hermanowicz-Salamon J, Chazan R: Expression of macrophage surface markers in induced sputum of patients with chronic obstructive pulmonary disease. J Physiol Pharmacol Off J Pol Physiol Soc 2006, 57(Suppl 4):75-84.

37. Hackett TL, Stefanowicz D, Aminuddin F, Sin DD, Connett JE, Anthonisen NR, Pare PD, Sandford AJ: Effect of gene environment interactions on lung function and cardiovascular disease in COPD. Int J Chronic Obstructive Pulm Dis $2011,6: 277-287$.
38. Jongepier H, Boezen HM, Dijkstra A, Howard TD, Vonk JM, Koppelman GH, Zheng SL, Meyers DA, Bleecker ER, Postma DS: Polymorphisms of the ADAM33 gene are associated with accelerated lung function decline in asthma. Clin Exp Allergy J Br Soc Allergy Clin Immunol 2004, 34:757-760

39. Washko GR, Dransfield MT, Estepar RS, Diaz A, Matsuoka S, Yamashiro T, Hatabu H, Silverman EK, Bailey WC, Reilly JJ: Airway wall attenuation: a biomarker of airway disease in subjects with COPD. J Appl Physio/ 2009, 107:185-191.

40. Yoshinaka T, Nishii K, Yamada K, Sawada H, Nishiwaki E, Smith K, Yoshino K, Ishiguro $H$, Higashiyama S: Identification and characterization of novel mouse and human ADAM33s with potential metalloprotease activity. Gene 2002, 282:227-236.

41. Kheradmand F, Rishi K, Werb Z: Signaling through the EGF receptor controls lung morphogenesis in part by regulating MT1-MMP-mediated activation of gelatinase A/MMP2. J Cell Sci 2002, 115:839-848.

42. Powell RM, Wicks J, Holloway JW, Holgate ST, Davies DE: The splicing and fate of ADAM33 transcripts in primary human airways fibroblasts. Am J Respir Cell Mol Biol 2004, 31:13-21.

43. Das M, Harvey I, Chu LL, Sinha M, Pelletier J: Full-length cDNAs: more than just reaching the ends. Physiol Genomics 2001, 6:57-80.

44. Umland SP, Garlisi CG, Shah H, Wan Y, Zou J, Devito KE, Huang WM, Gustafson EL, Ralston R: Human ADAM33 messenger RNA expression profile and post-transcriptional regulation. Am J Respir Cell Mol Biol 2003, 29:571-582.

45. Siafakas NM, Antoniou KM, Tzortzaki EG: Role of angiogenesis and vascular remodeling in chronic obstructive pulmonary disease. Int J Chronic Obstructive Pulm Dis 2007, 2:453-462.

46. Plataki M, Tzortzaki E, Rytila P, Demosthenes M, Koutsopoulos A, Siafakas NM: Apoptotic mechanisms in the pathogenesis of COPD. Int J Chronic Obstructive Pulm Dis 2006, 1:161-171.

47. Shapiro SD: Vascular atrophy and VEGFR-2 signaling: old theories of pulmonary emphysema meet new data. J Clin Invest 2000, 106:1309-1310.

48. Paulissen G, Rocks N, Gueders MM, Crahay C, Quesada-Calvo F, Bekaert S, Hacha J, El Hour M, Foidart JM, Noel A, Cataldo DD: Role of ADAM and ADAMTS metalloproteinases in airway diseases. Respir Res 2009, 10:127.

doi:10.1186/1471-2466-14-173

Cite this article as: Wang et al:: Genetic variants in ADAM33 are associated with airway inflammation and lung function in COPD. BMC Pulmonary Medicine 2014 14:173.

\section{Submit your next manuscript to BioMed Central and take full advantage of:}

- Convenient online submission

- Thorough peer review

- No space constraints or color figure charges

- Immediate publication on acceptance

- Inclusion in PubMed, CAS, Scopus and Google Scholar

- Research which is freely available for redistribution 